\title{
Letter from the Director
}

Policy Perspectives, the Trachtenberg School of Public Policy and Public Administration's superb student journal, is one of my favorite examples of how everyone in our school-faculty, students, and alumni-work to live out our motto of "doing good and doing it well."

This twenty-second volume of our student publication demonstrates again the ability of our students to research issues that are both timely and significant. Clint Trocchio, MPA '14, and Paul Miller, MPA '14, examine Washington, DC's system for regulating food trucks, one of the newest trends in urban cuisine. Theresa Anderson, MPP ' 12 and PhD candidate, explores a revenuebased approach to saving Social Security. While the challenges to the program have been known for decades, Anderson's ideas provide a new option for progress.

The research included in the volume addresses issues close to home and far afield. Laura Gibbons, MPP '15, considers the cost of inclusionary zoning and resale restrictions in Washington, DC, while Cinthia Josette Arévalo Gross, MPP '13 and PhD candidate, chronicles how the 2008-2009 economic crisis in Ecuador differentially affected women.

Finally, Sofie Miller, MPP '16, evaluates the effectiveness of government energy regulations while Daniel Walker, MPP '16, examines the origins of ineffective non-governmental organization practices.

Each of these articles benefited from student editors and faculty reviewers and from the authors' willingness to research, write, revise, research more, and then revise again.

This volume shows how public policy and administration theories and frameworks help us analyze and address real-world issues and challenges. Our student authors offer solid research and suggestions for improving systems and producing change for good.

These articles have the potential to inform policy deliberations in many forums. In addition to this print format, Policy Perspectives is also an online, open-access publication with the contents of the entire issue available at www. policy-perspectives.org. Each of the articles in this issue will receive a digital object identifier, which guarantees stable and enduring online access.

Policy analysts and others involved in policy formulation and implementation can find these articles through Google Scholar. Like the articles in the volumes that preceded this one, I am confident these articles will help public servants, policy analysts, and policy advocates to do good and do it well to serve the public good.

Kathryn Newcomer, PhD

Director

Trachtenberg School of Public Policy and Public Administration 